\title{
Hopfield Neural Network-Based Algorithm Applied to Differential Scanning Calorimetry Data for Kinetic Studies in Polymorphic Conversion
}

\author{
Bárbara C. R. Araujo, ${ }^{a}$ Felipe S. Carvalho, ${ }^{a}$ Maria Betânia F. Marques, ${ }^{a}$ \\ João Pedro Braga ${ }^{a}$ and Rita C. O. Sebastião ${ }^{\circledR *} * a$ \\ ${ }^{a}$ Departamento de Química, Instituto de Ciências Exatas, Universidade Federal de Minas Gerais, \\ Av. Antônio Carlos, 6627, 31270-901 Belo Horizonte-MG, Brazil
}

\begin{abstract}
A general kinetic equation to simulate differential scanning calorimetry (DSC) data was employed along this work. Random noises are used to generate a thousand data, which are considered to evaluate the performance of Levenberg-Marquardt (LM) and a Hopfield neural network (HNN) based algorithm in the fitting process. The HNN-based algorithm showed better results for two different initial conditions: exact and approximated values. After this statistical analysis, DSC experimental data at three heating rates for losartan potassium, an antihypertensive drug, was adjusted by the HNN method using different initial conditions to obtain the activation energy and frequency factor. Additionally, it was possible to recover the parameters for the kinetic model with accuracy, showing that the conversion is described by a complex process, once these values do not correspond to any ideal models described in the literature.
\end{abstract}

Keywords: kinetic study, neural network, DSC, thermal analysis

\section{Introduction}

Differential scanning calorimetry (DSC) is an accurate technique widely used to investigate the material thermal behavior and can be applied in kinetic studies on polymorphic conversion. ${ }^{1}$ In this experiment, the temperature is linearly increased and quantitative calorimetric information is obtained. ${ }^{2}$ The main physicalchemical properties investigated by this technique are the glass transition, ${ }^{3,4}$ heat capacity discontinuity in the glass transition, ${ }^{5}$ purity, ${ }^{6}$ heat of fusion and heat of reactions. Solid materials as polymers and drugs have their properties and/or kinetic of polymorphic conversion extensively explored by this technique..$^{7-9}$

Kinetic study from DSC experimental data assumes the process obeys Arrhenius law. The kinetic triplet (activation energy, pre-exponential factor and kinetic model) can be determined from the general equation:

$\frac{\mathrm{d} \alpha}{\mathrm{dT}}=\mathrm{A} / \beta \exp \left(-\frac{\mathrm{Ea}}{\mathrm{RT}}\right) \mathrm{f}(\alpha)$

with $\alpha$ as the conversion degree, $\beta$ the heating rate, $A$ the frequency factor, $\mathrm{E}_{\mathrm{a}}$ the activation energy, $\mathrm{R}$ the gas constant and $\mathrm{T}$ the temperature. A general kinetic model can be

*e-mail: ritacos@ufmg.br considered, $f(\alpha)=\alpha^{m}(1-q \alpha)^{n}$, in which the mechanism, depending on the $\mathrm{m}, \mathrm{n}$ and $\mathrm{q}$ parameters, describes the physics and chemistry of the process. ${ }^{10-12}$ Traditionally, equation 1 is used together with DSC data and fitted by Levenberg-Marquardt (LM) algorithm to determine the kinetic triplet. Neural network can also be used to successfully fit experimental data with high accuracy and reduced computational effort. ${ }^{13-16}$

The artificial neural network application to filter and deconvolute calorimetric signals was initially proposed by Sbirrazzuoli and Brunel. ${ }^{13}$ In their study, synthetic DSC curves were adjusted and the error analysis established by an objective function defined as the difference between synthetic and determined data.

In this work, the Hopfield neural network (HNN)-based algorithm is proposed to fit synthetic DSC curves and to retrieve the kinetic parameters $\left(\ln \mathrm{A}, \mathrm{E}_{\mathrm{a}}, \mathrm{m}, \mathrm{n}, \mathrm{q}\right)$. This procedure has already been explored by the present research group in other works. ${ }^{15-20}$ The performance of the network is investigated using a thousand curves with added random noise of $2.5 \%$ at point-by-point. Also, the proposed method is tested against LM algorithm with respect to accuracy and computational time to determine the parameters.

After this theoretical analysis, experimental data of losartan potassium (LOK), an antihypertensive drug, during its polymorphic conversion is investigated. To generalize 
the process as a complex kinetic, i.e., consider the occurrence of several mechanisms at same time, a general equation is used in the fit procedure. This assumption is validated since the retrieved parameters do not correspond to any ideal model.

\section{Methodology}

\section{Synthetic data}

DSC curves of heat flow, $\left(\frac{\mathrm{dH}}{\mathrm{dt}}\right)$, in a temperature interval can be simulated assuming a known transformation. For this, the activation energy, $\mathrm{E}_{\mathrm{a}}$, pre-exponential factor, $\mathrm{k}_{0}$, enthalpy $(\Delta \mathrm{H})$ and a mechanism, $\mathrm{f}(\alpha)$, are chosen and used in the kinetic equation:

$\left(\frac{\mathrm{d} \alpha}{\mathrm{dt}}\right)_{\mathrm{i}}=\mathrm{k}_{\mathrm{i}} \mathrm{f}\left(\alpha_{\mathrm{i}}\right)$

in which $\alpha_{\mathrm{i}}=\mathrm{H}_{\mathrm{i}} / \Delta \mathrm{H}$ and $\mathrm{H}_{\mathrm{i}}$ is the partial area calculated at time $i$. The rate constant is determined from Arrhenius law $\mathrm{k}_{\mathrm{i}}=\mathrm{k}_{0} \mathrm{e}^{-\frac{\mathrm{E}_{\mathrm{a}}}{\mathrm{RT}_{\mathrm{i}}}}$, with $\mathrm{R}$ the gas constant $\left(8.314 \mathrm{~J} \mathrm{~K}^{-1} \mathrm{~mol}^{-1}\right)$. Making the appropriate substitutions,

$\left(\frac{\mathrm{dH}}{\mathrm{dt}}\right)_{\mathrm{i}}=\Delta \mathrm{Hk}_{\mathrm{i}} \mathrm{f}\left(\alpha_{\mathrm{i}}\right)$

Sbirrazzuoli ${ }^{14,21}$ demonstrated that a mechanism for homogeneous kinetic processes as $f\left(\alpha_{i}\right)=\left(1-\alpha_{i}\right)^{n}$ is appropriate to describe a large amount of DSC curves. Thus, to determine DSC synthetic data it is necessary first to compute $\alpha_{\mathrm{i}}$ as,

$\int_{0}^{\alpha_{i}} \frac{d \alpha_{i}}{\left(1-\alpha_{i}\right)^{n}}=\int_{0}^{\alpha_{i}} k_{i} d t$

\section{Defining}

$\mathrm{S}_{\mathrm{i}}=\int_{0}^{\alpha_{\mathrm{i}}} \mathrm{k}_{\mathrm{i}} \mathrm{dt}$

one obtains

$\alpha_{\mathrm{i}}=1-\left[1+(\mathrm{n}-1) \mathrm{S}_{\mathrm{i}}\right]^{\frac{1}{1-\mathrm{n}}}$

The simulated DSC data is obtained from this result by means of equation 3 calculating $\alpha_{i}$ and its derivative in time. Taking the logarithm in equation 3 the general equation is established,

$\ln \left[\left(\frac{\mathrm{dH}}{\mathrm{dt}}\right)_{\mathrm{i}}\left(\frac{1}{\Delta \mathrm{H}}\right)\right]-\mathrm{n} \ln \left(1-\alpha_{\mathrm{i}}\right)=\ln \mathrm{A}-\frac{\mathrm{E}_{\mathrm{a}}}{\mathrm{RT}_{\mathrm{i}}}$
This equation is treated in the present work by LM and HNN-based algorithm to determine $\mathrm{n}$ as the reaction order, the activation energy, and the pre-exponential factor.

Nonlinear least-squares optimization and statistical analyses

To evaluate the performance of the LM and HNN-based algorithm it is necessary to establish a multi objective error function to the problem, given by

$\mathrm{E}=\sum_{\mathrm{r}=1}^{\mathrm{M}} \frac{1}{\mathrm{~N}} \sum_{\mathrm{i}=1}^{\mathrm{N}}\left(\mathrm{Y}_{\mathrm{r}, \mathrm{i}, \text { exp }}-\mathrm{Y}_{\mathrm{r}, \mathrm{i}, \mathrm{cal}}\right)^{2}$

in which $\mathrm{N}$ and $\mathrm{M}$ are the number of points and heating rates, respectively. $Y_{\mathrm{r}, \mathrm{i}, \mathrm{exp}}$ represents the synthetic heat flow by equation 3 and $Y_{r, i, c a l}$ is the recovered heat flow, both for the $r$-th heating rate at time $i$. The kinetic parameters are determined by fitting DSC data and is investigated considering 1000 synthetic $\mathrm{dH} / \mathrm{dt}(\mathrm{T})$ data for each heating rate with random errors of $2.5 \%$ point-by-point incorporated. This value of $2.5 \%$ in random noises was chosen since it is a common error in DSC experimental curves.

Levenberg-Marquardt (LM) fitting

The LM algorithm consists in using the first order regularization to solve a nonlinear problem. Applying the Newton's method in the error function,

$$
\mathrm{E}(\mathbf{w}+\delta \mathbf{w})=\mathrm{E}(\mathbf{w})+\frac{\mathrm{dE}(\mathbf{w})}{\mathrm{d} \mathbf{w}} \delta \mathbf{w}+\frac{\mathrm{d}^{2} \mathrm{E}(\mathbf{w})}{\mathrm{d}^{2}} \frac{(\delta \mathbf{w})^{2}}{2}
$$

with $\mathbf{w}$ as the vector of parameters, $\left(E_{a}, k_{o}\right.$ and $\left.n\right)$. At minimum, $\mathrm{E}(\mathbf{w}+\delta \mathbf{w})-\mathrm{E}(\mathbf{w})=0$ and therefore

$$
-\frac{\mathrm{dE}(\mathbf{w})}{\mathrm{d} \mathbf{w}}=\frac{\delta \mathbf{w}}{2} \frac{\mathrm{d}^{2} \mathrm{E}(\mathbf{w})}{\mathrm{d} \mathbf{w}^{2}}
$$

Considering the error function given by equation 8 ,

$$
\frac{\mathrm{dE}(\mathbf{w})}{d w_{j}}=2 \sum_{\mathrm{i}=1}^{\mathrm{m}} \mathrm{e}_{\mathrm{i}}(\mathbf{w}) \frac{\partial \mathrm{e}_{\mathrm{i}}(\mathbf{w})}{\partial \mathrm{w}_{\mathrm{j}}}=2 \mathbf{J}^{\mathrm{T}}(\mathbf{w}) \mathrm{e}(\mathbf{w})
$$

with $\mathrm{e}(\mathbf{w})=\left(\mathrm{Y}_{\mathrm{r}, \mathrm{i} \text { exp }}-\mathrm{Y}_{\mathrm{r}, \mathrm{i}, \text { cal }}(\mathbf{w})\right)$ and $\mathbf{J}$ the Jacobian matrix,

$$
\mathbf{J}=\left(\begin{array}{cccc}
\frac{\partial \mathrm{e}_{1}(\mathbf{w})}{\partial \mathrm{w}_{1}} & \frac{\partial \mathrm{e}_{1}(\mathbf{w})}{\partial \mathrm{w}_{2}} & \ldots & \frac{\partial \mathrm{e}_{1}(\mathbf{w})}{\partial \mathrm{w}_{\mathrm{n}}} \\
\frac{\partial \mathrm{e}_{2}(\mathbf{w})}{\partial \mathrm{w}_{1}} & \frac{\partial \mathrm{e}_{2}(\mathbf{w})}{\partial \mathrm{w}_{2}} & \cdots & \frac{\partial \mathrm{e}_{2}(\mathbf{w})}{\partial \mathrm{w}_{\mathrm{n}}} \\
\frac{\partial \mathrm{e}_{\mathrm{m}}(\mathbf{w})}{\partial \mathrm{w}_{1}} & \frac{\partial \mathrm{e}_{\mathrm{m}}(\mathbf{w})}{\partial \mathrm{w}_{2}} & \cdots & \frac{\partial \mathrm{e}_{\mathrm{m}}(\mathbf{w})}{\partial \mathrm{w}_{\mathrm{n}}}
\end{array}\right)
$$


To determine the term $\frac{d^{2} E(\mathbf{w})}{d \mathbf{w}^{2}}$ in equation 10 it may
explicit as

$$
\begin{aligned}
\frac{\partial^{2} \mathrm{E}(\mathbf{w})}{\partial \mathrm{w}_{\mathrm{k}} \mathrm{w}_{\mathrm{j}}} & =2 \sum_{\mathrm{i}=1}^{\mathrm{m}}\left[\frac{\partial \mathrm{e}_{\mathrm{i}}(\mathbf{w})}{\partial \mathrm{w}_{\mathrm{k}}} \frac{\partial \mathrm{e}_{\mathrm{i}}(\mathbf{w})}{\partial \mathrm{w}_{\mathrm{j}}}+\mathrm{e}_{\mathrm{i}}(\mathbf{w}) \frac{\partial^{2} \mathrm{e}_{\mathrm{i}}(\mathbf{w})}{\partial \mathrm{w}_{\mathrm{k}} \mathrm{w}_{\mathrm{j}}}\right] \\
& =2 \mathbf{J}^{\mathrm{T}}(\mathbf{w}) \mathbf{J}(\mathbf{w})+2 \mathrm{~S}(\mathbf{w})
\end{aligned}
$$

Considering that $\mathrm{S}(\mathbf{w})$ contribution is not relevant, $\frac{\partial^{2} \mathrm{E}(\mathbf{w})}{\partial \mathrm{w}_{\mathrm{k}} \mathrm{w}_{\mathrm{j}}}=2 \mathbf{J}^{\mathrm{T}}(\mathbf{w}) \mathbf{J}(\mathbf{w})$. Using this result along equations 10 and 11 , the parameters can be obtained by solving

$\delta \mathbf{w}=-2\left(\mathbf{J}^{\mathrm{T}} \mathbf{J}\right)^{-1} \mathbf{J}^{\mathrm{T}} \mathrm{e}(\mathbf{w})$

However, in this work, it is assumed the first-order regularization in equation 13 ,

$\delta \mathbf{w}=-2\left(\mathbf{J}^{\mathrm{T}} \mathbf{J}+\mu \mathbf{I}\right)^{-1} \mathbf{J}^{\mathrm{T}} \mathrm{e}(\mathbf{w})$

with $\mathbf{I}$ being the identity matrix and $\mu$ as the regularization parameter.

\section{Hopfield neural network (HNN) fitting}

HNN is a recurrent single-layer network with all logic units connected. The neurons are connected by a weight factor, $\mathrm{T}_{\mathrm{ij}}$, between the neurons $\mathrm{i}$ and $\mathrm{j}$. The state of a neuron, $\mathrm{u}_{\mathrm{i}}$, is determined by a weighted sum of all neurons connected to it and by external impulses, $\mathrm{I}_{\mathrm{i}}$ as

$\mu_{i} \frac{d u_{i}(t)}{d t}=-u_{i}(t)+\left[\sum_{j=1}^{n} T_{i j} f\left(u_{j}(t)\right)+I_{i}(t)\right]$

This equation represents the HNN with the corresponding learning rate, $\mu_{i}$, usually equals to one. In equation $16, \mathrm{u}_{\mathrm{i}}(\mathrm{t})$ is the neuron state $\mathrm{i}$ at time $(\mathrm{t})$ and $\mathrm{f}\left(\mathrm{u}_{\mathrm{j}}(\mathrm{t})\right)$ is the activated state of all neurons connected to neuron $i$. The neuron state must be activated by a function, $\mathrm{f}$, defined as activation function, which is monotonically crescent, continuous and well-behaved.

Representing the individual error in equation 8:

$\mathrm{e}(\mathbf{w}+\delta \mathbf{w})=\mathrm{e}(\mathbf{w})+\frac{\partial \mathrm{e}}{\partial \mathbf{w}} \delta \mathbf{w}$

At minimum the problem to be solved by the HNN is represented as,

$\mathbf{J}(\mathbf{w}) \delta \mathbf{w}=-\mathrm{e}(\mathbf{w})$

with $\mathbf{J}(\mathbf{w})$ the Jacobian matrix. Considering $\delta \mathbf{w}_{\mathrm{i}}=\mathrm{f}_{\mathrm{i}}=\mathrm{f}\left(\mathrm{u}_{\mathrm{i}}(\mathrm{t})\right)$ the temporal derivative of error function, equation 8 , is calculated as

$\frac{d E}{d t}=\sum_{i=1}^{n} \frac{\partial E}{\partial f_{i}} \frac{\partial f_{i}}{\partial u_{i}} \frac{d u_{i}}{d t}$

If the condition $\frac{\mathrm{dE}}{\mathrm{dt}}<0$ is imposed, i.e., a decreasing error over time, and since $\frac{\partial f}{\partial u}>0$, one is left with

$\frac{\mathrm{du}_{\mathrm{i}}}{\mathrm{dt}}=-\frac{\partial \mathrm{E}}{\partial \mathrm{f}_{\mathrm{i}}}$

Assuming the error function of equation 8 , this equation can be represented as

$$
\begin{aligned}
\frac{d u_{i}}{d t}= & -\left(\left(\sum_{j=1}^{n} J_{1 j} f_{j}-e_{1}\right)\right) J_{1 i}-\left(\left(\sum_{j=1}^{n} J_{2 j} f_{j}-e_{2}\right)\right) J_{2 i} \\
& -\ldots\left(\left(\sum_{j=1}^{n} J_{m j} f_{j}-e_{m}\right)\right) J_{m i}
\end{aligned}
$$

Therefore, the neurons temporal evolution in the network is given by

$\frac{d u_{i}}{d t}=\sum_{j=1}^{n} T_{i j} f_{j}+I_{i}$

with

$T_{i j}=-\sum_{l=1}^{m} J_{1 i} J_{1 j}=T_{j i} \quad I_{i}=\sum_{j=1}^{m} J_{j i} e_{j}$

To solve equation 22 it is used a fourth order RungeKutta method. The feature of multiple solutions is observed during this integration process. The learning process consists of the actualization of parameters considered in the error function and it is stopped when the neural network learned about the process, i.e., $\frac{\partial \mathbf{u}_{\mathrm{i}}}{\partial \mathrm{t}}=0$.

\section{Experimental data}

The thermal behavior of LOK was determined using DSC60 Shimadzu cell (Tokyo, Japan), calibrated with indium (melting point: $\mathrm{T}_{\text {onset }}=156.63^{\circ} \mathrm{C}, \Delta \mathrm{H}_{\text {fus }}=28.45 \mathrm{~J} \mathrm{~g}^{-1}$ ) under dynamic nitrogen atmosphere at $50 \mathrm{~mL} \mathrm{~min}^{-1}$, under heating rate of 8,10 and $12{ }^{\circ} \mathrm{C} \mathrm{min}-1$, from 30 to $400{ }^{\circ} \mathrm{C}$, in closed aluminum crucible and sample mass, accurately about $1.5 \mathrm{mg}$. The thermogravimetric (TG) curve was obtained in a Shimadzu DTG60 thermobalance (Tokyo, Japan) with heating rate of $10{ }^{\circ} \mathrm{C} \mathrm{min}^{-1}$, from 30 to $600{ }^{\circ} \mathrm{C}$, dynamic nitrogen atmosphere at $50 \mathrm{~mL} \mathrm{~min}^{-1}$, in alumina crucible and mass of sample accurately weighted about $2.5 \mathrm{mg}$. 


\section{Results and Discussion}

Computation of DSC curves incremented with experimentallike statistical noisy

The kinetic parameters of activation energy $\mathrm{E}_{\mathrm{a}}=74 \mathrm{~kJ} \mathrm{~mol}^{-1}$ and pre-exponential factor $\ln \left(\mathrm{k}_{0}\right)=18$ together with the mechanism order $n=2$ in equation 7 , were considered to produce the synthetic data in the temperature interval from 353 to $453 \mathrm{~K}$ (this temperature interval is due to the kinetic parameters chosen to produce the synthetic data). Following equation 6 , one computed the $\alpha_{\mathrm{i}}$ data and its derivative curve to determine $\mathrm{dH}_{\mathrm{i}} / \mathrm{dt}$ as in equation 3 , with $\Delta \mathrm{H}=77 \mathrm{~kJ}$. Considering experimental data, the result for $\alpha_{i}$ should be computed using $\alpha_{\mathrm{i}}=\mathrm{H}_{\mathrm{i}} / \Delta \mathrm{H}$, with $\mathrm{H}_{\mathrm{i}}$ as the partial area calculated at time i. To test numerically the synthetic data, the $\alpha_{i}$ values were calculated from both equations and are represented in Figure 1 for three different heating rates. It is observed that both methods provide results in fair agreement. Figure 2 presents the synthetic data for $\mathrm{dH}_{\mathrm{i}} / \mathrm{dt}$ determined from the $\alpha_{\mathrm{i}}$ curves and another 1000 curves with $2.5 \%$ random noises added point-by-point.

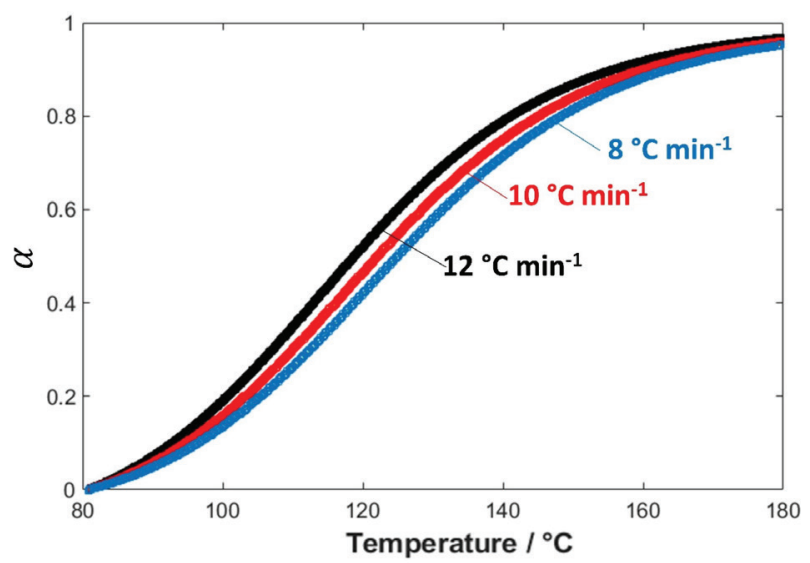

Figure 1. The $\alpha_{i}$ curves computed as equation 5 (solid line) and as $\alpha_{\mathrm{i}}=\mathrm{Hi} / \Delta \mathrm{H}$ (squares). The curves are superimposed in this scale.

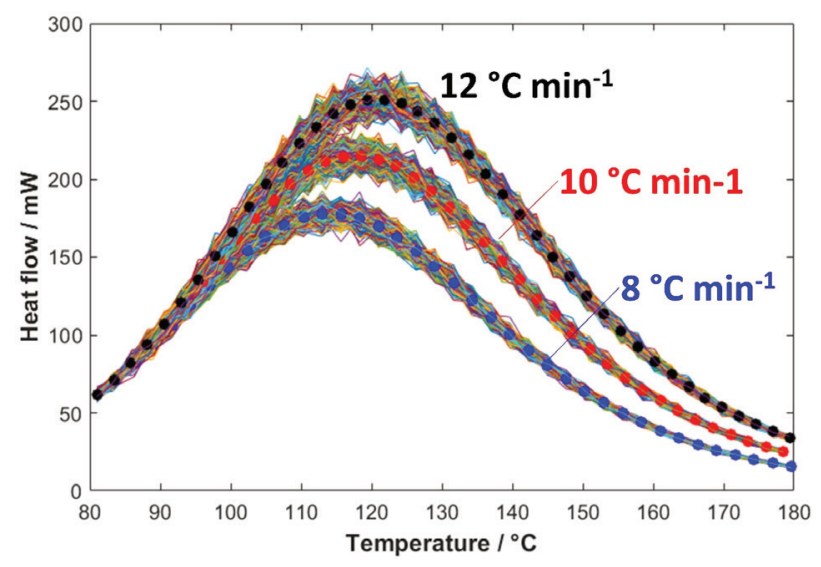

Figure 2. Simulated DSC data. Original curve obtained from $\alpha_{i}$ curve (*) and one thousand added noise curves (colored shadow).

\section{Comparative results of LM and HNN-based algorithm}

Case 1: The process is known and the kinetic parameters is provided to confirm the kinetics

In this case the process is known and the correct parameters are provided to the algorithms. One hundred simulated points equally spaced in the temperature domain were used in each curve. Figure 3 presents the histogram of parameters determined by fitting the 1000 curves of $\mathrm{dH}_{\mathrm{i}} / \mathrm{dt}$ with noise. The retrieved parameters and standard deviations computed by the LM and HNN-based methods are shown in Table 1. Fitting procedure with both algorithms presented results very close to the exact value used to simulate the data, $\mathrm{E}_{\mathrm{a}}=74 \mathrm{~kJ} \mathrm{~mol}^{-1}, \ln \left(\mathrm{k}_{0}\right)=18$ and $\mathrm{n}=2$. The calculated parameters also showed smaller standard deviations in both cases. This small dispersion around the exact value indicates a good accuracy of the methods.

An important aspect to be highlighted is the computational time in both algorithms. These results are presented in Table 2. Although the LM method accuracy, the HNN fitting algorithm is 535 times faster.

The adjustment by HNN and LM are presented in Figure 2 for three heating rates and simulated data without

Table 1. Results and standard deviations of $\mathrm{E}_{\mathrm{a}}, \ln \left(\mathrm{k}_{0}\right)$ and $\mathrm{n}$ by $\mathrm{LM}$ and HNN

\begin{tabular}{|c|c|c|c|c|c|c|}
\hline \multirow{2}{*}{ Study of case } & \multirow{2}{*}{ Parameter } & \multirow{2}{*}{ Theoretical value } & \multicolumn{2}{|c|}{ LM } & \multicolumn{2}{|c|}{$\mathrm{HNN}$} \\
\hline & & & Result & Standard deviation & Result & Standard deviation \\
\hline \multirow{3}{*}{ Case 1} & $\mathrm{E}_{\mathrm{a}} /\left(\mathrm{kJ} \mathrm{mol}^{-1}\right)$ & 74 & 74.1 & 0.5 & 74.0 & $2.0 \times 10^{-8}$ \\
\hline & $\ln \left(\mathrm{k}_{0}\right)$ & 18 & 18.0 & 0.2 & 18.0 & $2.0 \times 10^{-5}$ \\
\hline & $\mathrm{n}$ & 2 & 2.0 & $2.0 \times 10^{-4}$ & 2.0 & $2.0 \times 10^{-6}$ \\
\hline \multirow{3}{*}{ Case 2} & $\mathrm{E}_{\mathrm{a}} /\left(\mathrm{kJ} \mathrm{mol}^{-1}\right)$ & 74 & 74.0 & 2 & 74.0 & $2.0 \times 10^{-6}$ \\
\hline & $\ln \left(\mathrm{k}_{0}\right)$ & 18 & 18.0 & 1 & 18.0 & $2.0 \times 10^{-3}$ \\
\hline & $\mathrm{n}$ & 2 & 2.0 & 0.3 & 2.0 & $2.0 \times 10^{-2}$ \\
\hline
\end{tabular}

LM: Levenberg-Marquardt; HNN: Hopfield neural network; $\mathrm{E}_{\mathrm{a}}$ : activation energy; $\ln \left(\mathrm{k}_{0}\right)$ : logarithm of pre-exponential factor; $\mathrm{n}$ : reaction order. 

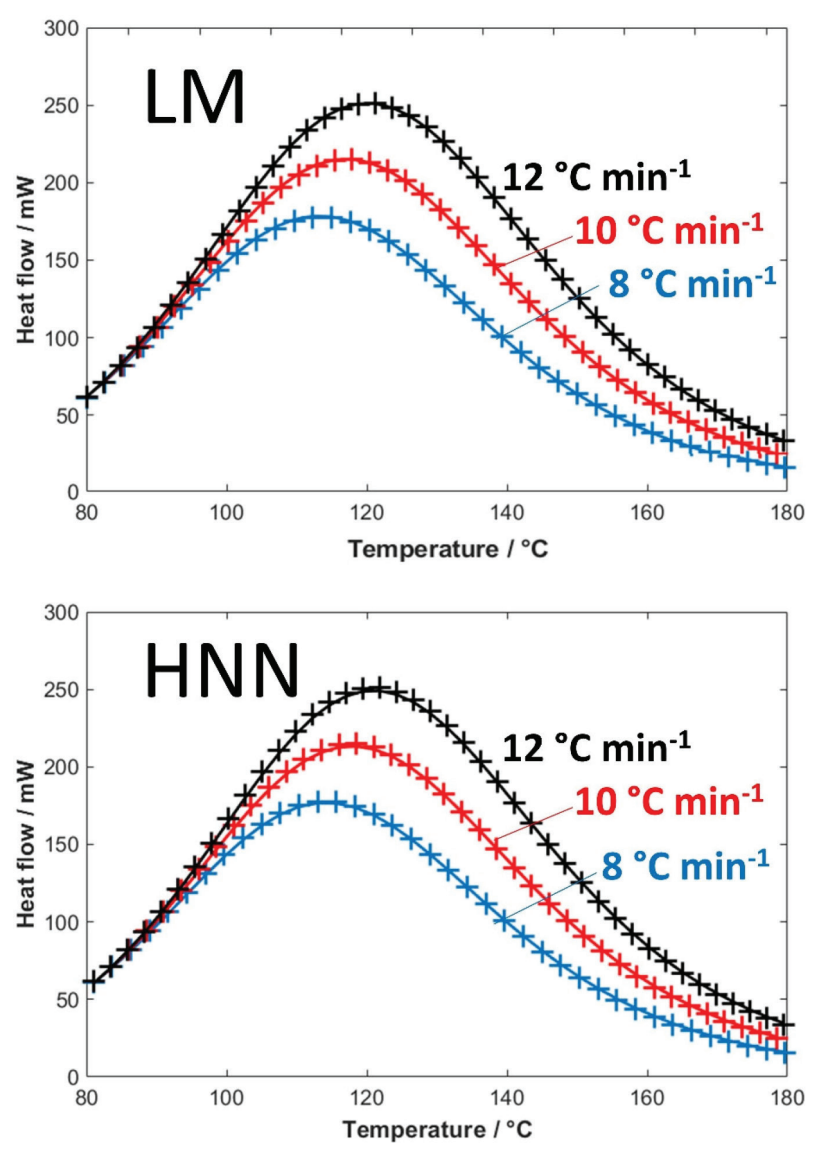

Figure 3. Simulated data adjustment by Levenberg-Marquardt (LM) and neural network (HNN)-based methods.

Table 2. Elapsed time for fitting procedure spent by LM and HNN

\begin{tabular}{lcc}
\hline Study of case & Optimization method & Elapsed time / h \\
\hline \multirow{2}{*}{ Case 1} & HNN & 0.013 \\
& LM & 6.958 \\
\hline \multirow{2}{*}{ Case 2} & HNN & 0.011 \\
& LM & 1.360 \\
\hline
\end{tabular}

HNN: Hopfield neural network; LM: Levenberg-Marquardt.

error for the case 1 analysis. The fair agreement among the retrieved curves and the simulated data corroborates the potentiality of both methods.

Figure 4 shows the computed histograms of the parameters retrieved by LM and HNN-based algorithm for the 1000 DSC synthetic curves with random noise. The thinner histogram for HNN-based algorithm demonstrate the accuracy of this method if compared with LM.

Case 2: The process is unknown but an estimative is provided to test the algorithms

In this case no information is known about the process, but an estimative for the parameters are provided as initial guess to the algorithms. One defined as a first estimative

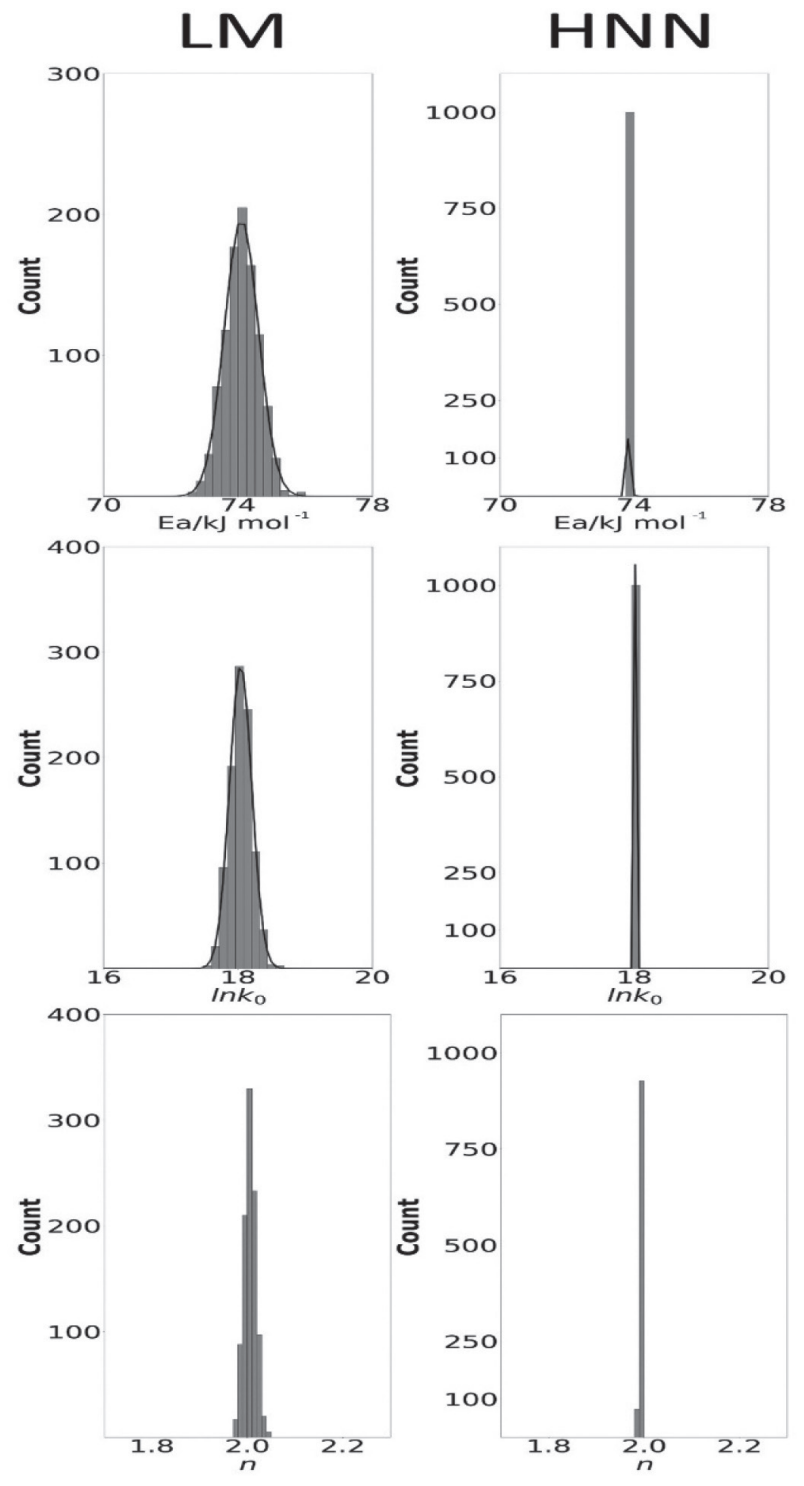

Figure 4. Histograms of $E_{a}, \ln \left(k_{0}\right)$, and $n$ retrieved by Levenberg-Marquardt (LM) and neural network (HNN)-based method for the case 1 analysis.

$\mathrm{E}_{\mathrm{a}}=100 \mathrm{~kJ} \mathrm{~mol}^{-1}, \ln \left(\mathrm{k}_{0}\right)=10$ and $\mathrm{n}=0$ and used the same 1000 DSC curves incremented with $2.5 \%$ noise. Figure 5 presents the histograms obtained by LM and HNN-based algorithms. The results for each parameter and the corresponding standard deviation are shown in Table 1. The HNN-based algorithm showed, also in this case, thinner histograms for all parameters, proving to be more precise.

For adequate drug products manufacturing by pharmaceutical industry, a detailed description of material composition and process instructions are required. For example, it is very important to know about any physical or chemical transformation in the substances, as the polymorphic conversion in losartan potassium. This knowledge guarantees public health and it is predicted 

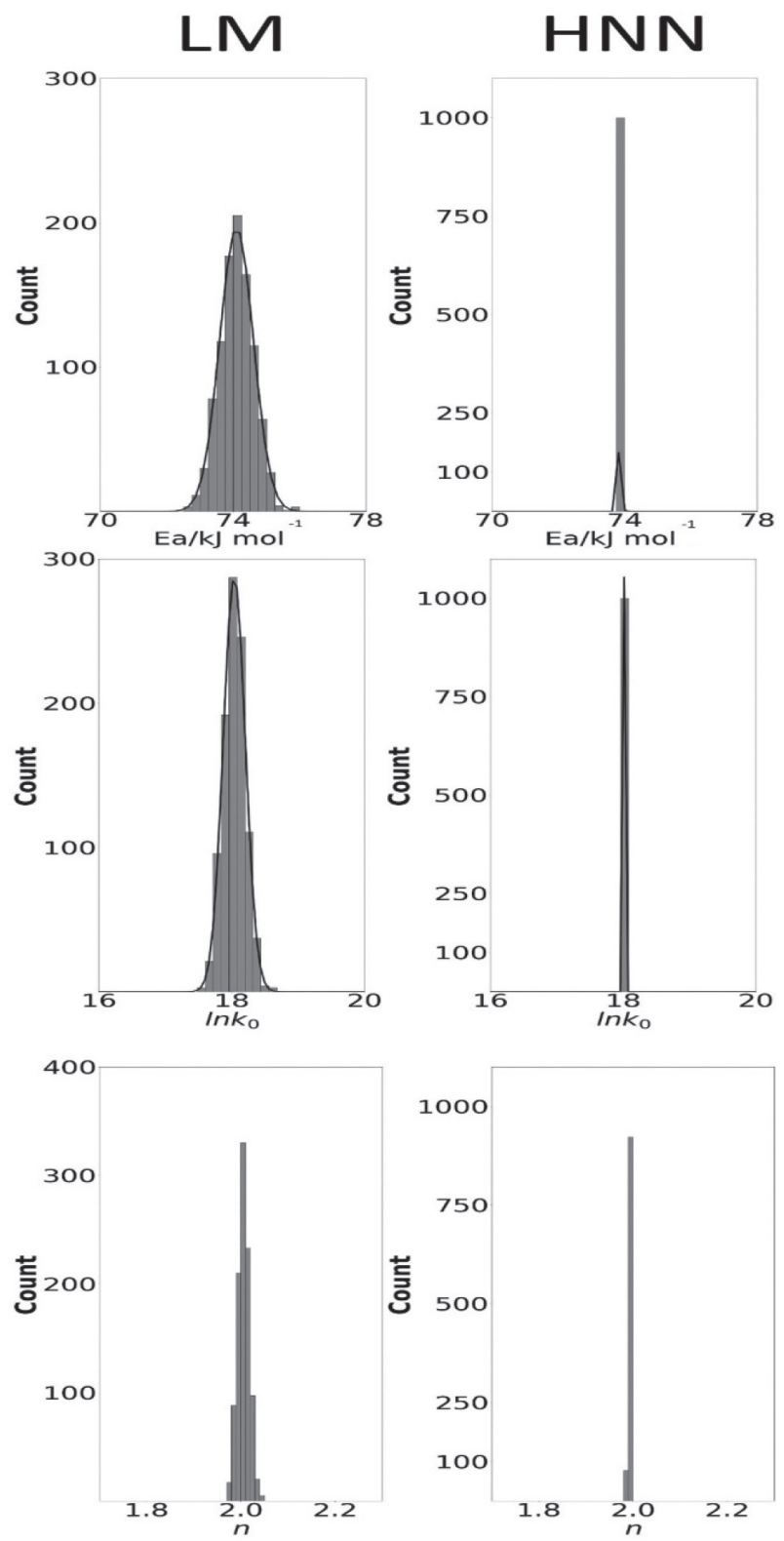

Figure 5. Histograms of kinetic parameters computed by LM and HNNbased methods using an estimative for the initial guess.

by Good Manufacturing Practices (GMP) as required by regulatory agencies. ${ }^{22,23}$ Therefore the use of analytical techniques, such as DSC curves, together with accurate and robust methodology, as HNN, that presents runtime compatible with the market dynamics and meet the Pharmaceutical Quality System, are fundamental for drug production and obeys the quality standards, required by regulatory agencies and the market. ${ }^{20,24}$

HNN can be a robust tool applied to Process Analytical Technology (PAT) described within Quality by Design $(\mathrm{QbD})$ as emerging systems for quality assurance in pharmaceutical processes..$^{25-27}$ Therefore it is a promising routine methodology for the treatment of DSC data applied in polymorphic conversion kinetic studies, as shown for potassium losartan in the next section.

\section{Experimental results: losartan potassium}

LOK is an orally active antihypertensive agent, nonpeptide-angiotensin II receptor antagonist with no side effects, which proves its efficacy, safety and therefore its clinical relevance. ${ }^{28}$ The occurrence of polymorphism in LOK was previously described ${ }^{29}$ and the conversion of LOK form I to LOK form II can be induced by heat. ${ }^{30}$ In this work one proposed to study the kinetic of this polymorphic conversion using DSC data applying the HNN-based algorithm.

DSC curve of LOK (Figure 6, solid line) shows a small endothermic event between $228-245{ }^{\circ} \mathrm{C}$ (in a circle), without mass loss as shows TG curve (Figure 6, short dot line), which corresponds to an enantiotropic conversion of form I to form II $\left(\mathrm{T}_{\text {onset }}=231.3{ }^{\circ} \mathrm{C}, \Delta \mathrm{H}=13.16 \mathrm{~J} \mathrm{~g}^{-1}\right)$. These two polymorphic forms were confirmed by X-ray powder diffraction as previously described.$^{29} \mathrm{~A}$ remarkable endothermic peak at $271.5^{\circ} \mathrm{C}\left(\mathrm{T}_{\text {onset }}\right)$ with enthalpy of $95.1 \mathrm{~J} \mathrm{~g}^{-1}$ (without mass loss, as shows in TG curve) represents the form II melting. Then, decomposition process starts at $278{ }^{\circ} \mathrm{C}$ with mass loss of $55 \%$ in three steps, as can be observed in the TG curve. These results refer to the heating rate at $10{ }^{\circ} \mathrm{C} \mathrm{min}{ }^{-1}$.

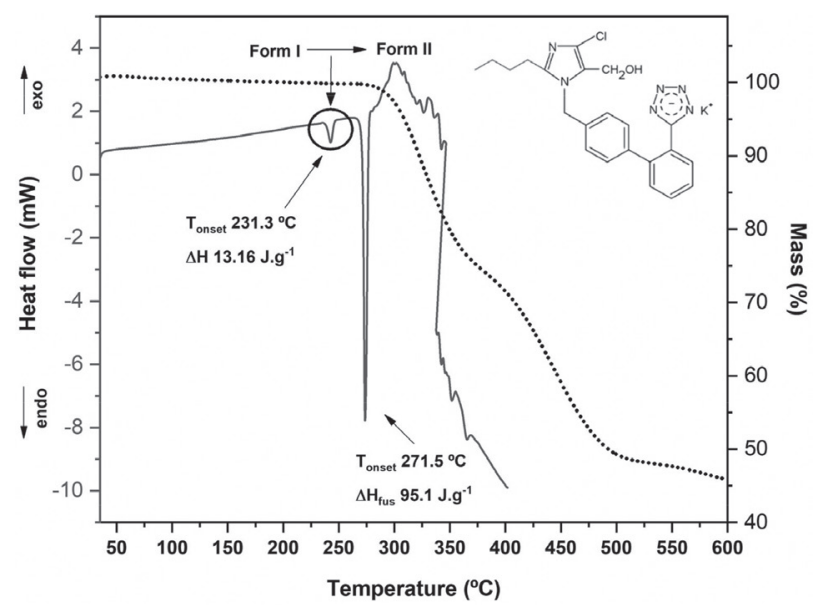

Figure 6. DSC (solid line) and TG (dotted line) curves of losartan potassium. Form I convert to form II at $231.3{ }^{\circ} \mathrm{C}\left(\mathrm{T}_{\text {onset }}\right)$. The form II melting at $271.5^{\circ} \mathrm{C}\left(\mathrm{T}_{\text {onset }}\right)$. The graphic representation of losartan potassium molecule is on detail.

Experimental data acquired at three heating rates $(8$, 10 and $12{ }^{\circ} \mathrm{C} \mathrm{min}^{-1}$ ) were considered and HNN and LM methods used to fit equation 7 in a multi objective function, as equation 8 . Three different heating rates were used to attend International Confederation for Thermal Analysis and Calorimetry (ICTAC) recommendations for an accurate 
determination of kinetic parameters. ${ }^{31}$ Nevertheless, neither HNN nor LM algorithms presented reasonable adjustments. This result suggests the proposed model in equation 7 is not adequate to describe the LOK conversion process. Thus, a general kinetic model ${ }^{11,12}$ was used to effectively describe the experimental data as,

$\ln \left[\left(\frac{\mathrm{dH}}{\mathrm{dt}}\right)_{\mathrm{i}}\left(\frac{1}{\Delta \mathrm{H}}\right)\right]-\ln \left(\alpha_{\mathrm{i}}^{\mathrm{m}}\left(1-\mathrm{q} \alpha_{\mathrm{i}}\right)^{\mathrm{n}}\right)=\ln \mathrm{A}-\frac{\mathrm{E}_{\mathrm{a}}}{\mathrm{RT}_{\mathrm{i}}}$

HNN algorithm determined $\ln \mathrm{A}, \mathrm{E}_{\mathrm{a}}, \mathrm{m}, \mathrm{n}, \mathrm{q}$, by adjusting experimental data with three heating rates. Table 3 presents the results together with the residual errors. Since the term $k_{i}=k_{0} e^{-\frac{E_{a}}{R T_{i}}}$ in equations 2 and 3 accept several combinations of $\mathrm{k}_{0}$ and $\mathrm{E}_{\mathrm{a}}$ which guarantee the correct amplitude for $\left(\frac{\mathrm{dH}}{\mathrm{dt}}\right)_{\mathrm{i}}$ and $\left(\frac{\mathrm{d} \alpha}{\mathrm{dt}}\right)_{\mathrm{i}}$, it is necessary to analyze the initial conditions given to start the minimization process. Results of $\mathrm{k}_{0}$ and $\mathrm{E}_{\mathrm{a}}$ for different initial conditions (keeping the initial conditions for $\mathrm{m}=1.0, \mathrm{q}=1.0$ and $\mathrm{n}=1.0$ ) are presented in Table 3 . To analyze the sensitivity of the method, we used slightly different values for $\mathrm{k}_{0}$ and $\mathrm{E}_{\mathrm{a}}$ as initial conditions. A difference smaller than $10 \mathrm{~s}^{-1}$ for the frequency factor and $10 \mathrm{~kJ} \mathrm{~mol}^{-1}$ in the activation energy is enough to provide different values for these retrieved parameters. Although, the model remains unchanged for several tested initial conditions. In this calculation, the tolerance in sum squared error was set to be of $10^{-6}$. The root mean squared deviation, rmsd, is calculated as follows:

$\mathrm{rmsd}=\sum_{\mathrm{r}=1}^{3} \sqrt{\frac{\sum_{\mathrm{i}=1}^{\mathrm{N}}\left(\left(\frac{\mathrm{dH}}{\mathrm{dt}}\right)_{\mathrm{r}, \mathrm{i}(\mathrm{calc})}-\left(\frac{\mathrm{dH}}{\mathrm{dt}}\right)_{\mathrm{r}, \mathrm{i} \text { (exa) }}\right)^{2}}{\mathrm{~N}}}$

in which the term $\left(\frac{\mathrm{dH}}{\mathrm{dt}}\right)_{\mathbf{r}, \text { (exa) }}$ is the experimental and
$\left(\frac{\mathrm{dH}}{\mathrm{dt}}\right)_{\mathbf{r}, \text { (calc) }}$ is the calculated data for $\mathrm{N}$ data points, both at each heating rate $r$.

From Table 3, we can observe that all results are chemically acceptable. As all these solutions are physically coherent, it is possible to choose the solution with the smaller rmsd, although this parameter varies only in the $3^{\text {rd }}$ decimal place. Therefore, one can infer that LOK conversion is described assuming the parameters $\mathrm{k}_{0}=6.376 \times 10^{12} \mathrm{~s}^{-1}, \mathrm{E}_{\mathrm{a}}=136.5 \mathrm{~kJ} \mathrm{~mol}^{-1}, \mathrm{~m}=0.6, \mathrm{n}=0.85$ and $\mathrm{q}=1.0$. It infers that the process occurs as a complex event, once these values do not correspond to any ideal kinetic model. The smaller rmsd solution and the LOK experimental data are shown in Figure 7.

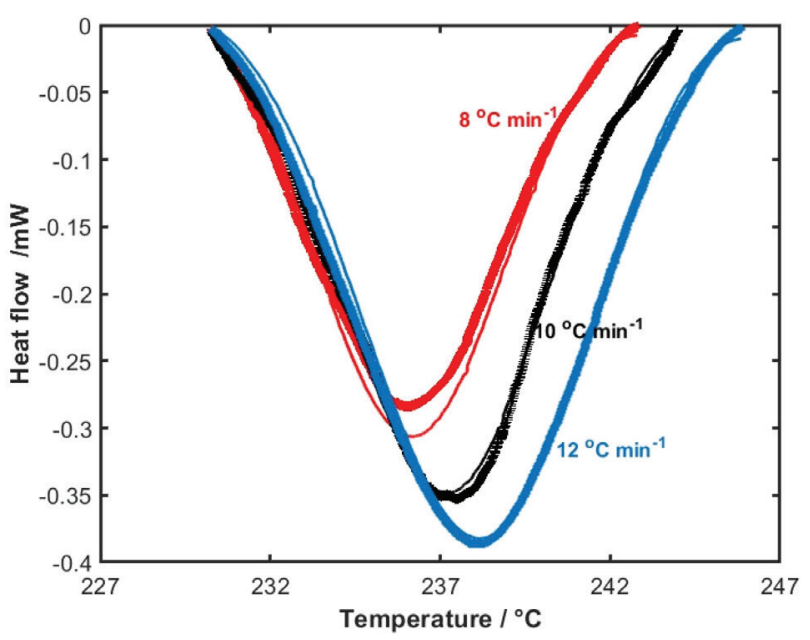

Figure 7. Experimental data $(*)$ and HNN adjustment (solid line).

Figure 8 presents the residual error evolution over time for HNN method. It can be seen the convergence of the neural network about the eightieth iteration. Together with this analysis, the Figure 9 also demonstrates the convergence of the HNN method representing the evolution of the artificial neurons over time. From this figure, one can observe the states of artificial neurons converging for

Table 3. Retrieved kinetic parameters $\mathrm{k}_{0}, \mathrm{E}_{\mathrm{a}}, \mathrm{m}, \mathrm{n}$, $\mathrm{q}$ and residual errors to fit the LOK experimental data with different initial conditions

\begin{tabular}{|c|c|c|c|c|c|c|c|}
\hline \multicolumn{2}{|c|}{ Initial condition } & \multicolumn{5}{|c|}{ Retrieved kinetic parameters } & \multirow{2}{*}{ rmsd } \\
\hline $\mathrm{k}_{0} / \mathrm{s}^{-1}$ & $\mathrm{E}_{\mathrm{a}} /\left(\mathrm{kJ} \mathrm{mol}^{-1}\right)$ & $\mathrm{k}_{0} / \mathrm{s}^{-1}$ & $\mathrm{E}_{\mathrm{a}} /\left(\mathrm{kJ} \mathrm{mol}^{-1}\right)$ & $\mathrm{m}$ & $\mathrm{n}$ & $\mathrm{q}$ & \\
\hline $1.0 \times 10^{12}$ & 130.00 & $1.860 \times 10^{13}$ & 141.47 & 0.59 & 0.81 & 1.00 & 0.110 \\
\hline $2.0 \times 10^{12}$ & 140.00 & $3.484 \times 10^{13}$ & 144.11 & 0.59 & 0.81 & 1.00 & 0.110 \\
\hline $5.0 \times 10^{11}$ & 130.00 & $7.070 \times 10^{12}$ & 137.37 & 0.59 & 0.81 & 0.998 & 0.115 \\
\hline $6.0 \times 10^{11}$ & 130.00 & $1.804 \times 10^{13}$ & 141.35 & 0.59 & 0.81 & 1.00 & 0.110 \\
\hline $2.0 \times 10^{12}$ & 140.00 & $6.376 \times 10^{12}$ & 136.89 & 0.59 & 0.81 & 0.998 & 0.0098 \\
\hline $2.0 \times 10^{12}$ & 130.00 & $6.376 \times 10^{12}$ & 136.52 & 0.60 & 0.85 & 1.00 & 0.0052 \\
\hline
\end{tabular}

$\mathrm{k}_{0}$ : pre-exponential factor; $\mathrm{E}_{\mathrm{a}}$ : activation energy; $\mathrm{m}, \mathrm{n}$, q: parameters of the general kinetic model; rmsd: root mean squared deviation. 


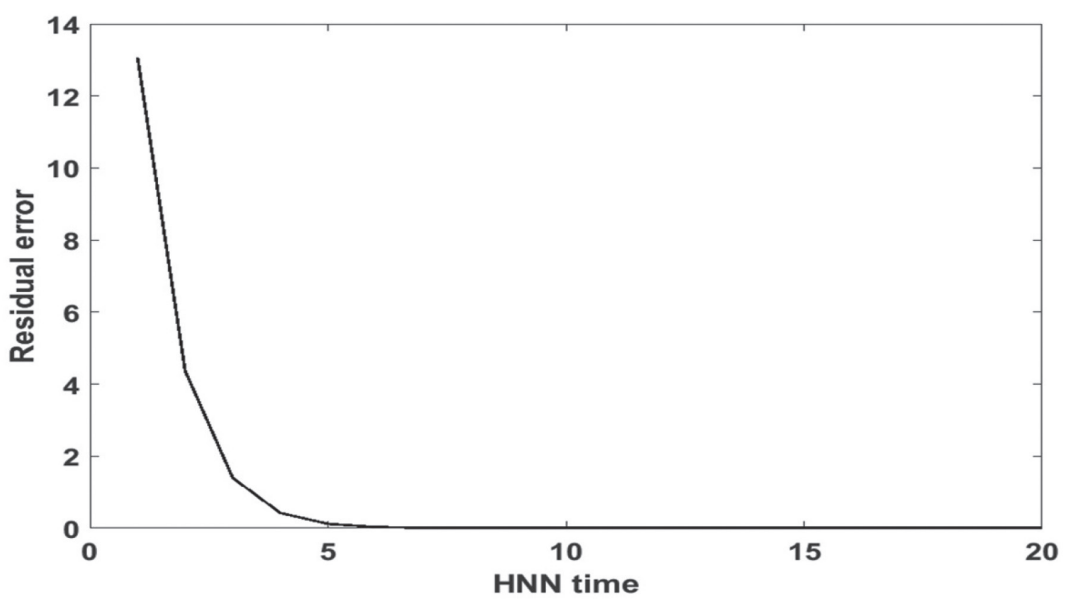

Figure 8. Residual error evolution during the HNN learning time.

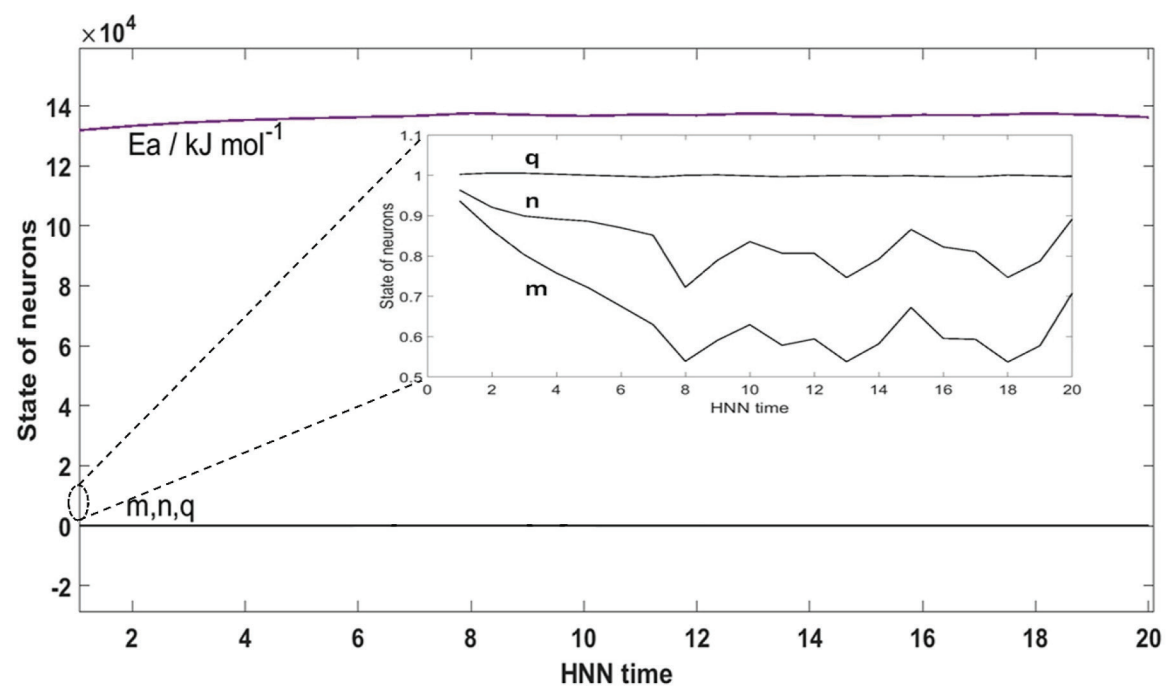

Figure 9. Evolution of artificial neurons during the HNN learning time.

$\mathrm{q}=1, \mathrm{n}$ as an average value between 0.75 and 0.9 and the $\mathrm{m}$ parameter as an average value between 0.55 and 0.65 . The activation energy is about $135 \mathrm{~kJ} \mathrm{~mol}^{-1}$ and the $\mathrm{k}_{0}$ parameter as an average value between $2.0 \times 10^{13}$ and $6.0 \times 10^{12} \mathrm{~s}^{-1}$. The $\mathrm{k}_{0}$ is not in this figure because of the scale.

\section{Conclusions}

The HNN methodology has some advantages over conventional optimization algorithms-in this case LM-in terms of adaptability and robustness to treat experimental error and unknown initial guess in the kinetic studies using DSC experimental data. Even if an unknown value is provided as initial guess, the HNN algorithm converges for the correct answer presenting a narrow normal distribution about the correct values, as seen from simulated data. The kinetics of polymorphic conversion event in losartan potassium employing this method was performed and the results imply a process that occurs as a complex event, involving the contribution of various kinetic models, once the $\mathrm{m}, \mathrm{n}$ and q parameters do not correspond to any ideal model. Also, it was observed a small residual error to fit the experimental data, for the activation energy of $135 \mathrm{~kJ} \mathrm{~mol}^{-1}$ and frequency factor of $6.376 \times 10^{12} \mathrm{~s}^{-1}$.

Since the model parameters have non-sensitivity to initial conditions it is possible to obtain $\mathrm{m}, \mathrm{n}$ and $\mathrm{q}$ with great precision and hence confirm that the polymorphic conversion occurs as a complex process. Nevertheless, to accurately determine the activation energy and frequency factor parameters it is necessary data for several heating rates, as presented by Ozawa. ${ }^{32}$

\section{Acknowledgments}

This study was financed in part by the Coordenação de Aperfeiçoamento de Pessoal de Nível Superior Brasil (CAPES)-Finance Code 001. The authors also thank Conselho Nacional de Desenvolvimento Científico e 
Tecnológico (CNPq) and Fundação de Amparo à Pesquisa do Estado de Minas Gerais (FAPEMIG) for financial support.

\section{References}

1. Koh, Y. P.; Simon, S. L.; J. Chem. Phys. 2017, 146, 203329.

2. Menczel, J. D.; Prime, R. B.; Thermal Analysis of Polymers: Fundamentals and Applications; John Wiley \& Sons: New Jersey, 2014.

3. Cui, H.-W.; Kuo, S.-W.; Appl. Clay Sci. 2014, 91-92, 1.

4. Sahoo, K. L.; Sahu, R.; J. Non-Cryst. Solids 2013, 365, 33.

5. Holubová, J.; Černošková, E.; Černošek, Z.; J. Therm. Anal. Calorim. 2013, 111, 1633.

6. Kut'in, A. M.; Plekhovich, A. D.; Balueva, K. V.; Motorin, S. E.; Dorofeev, V. V.; Thermochim. Acta 2019, 673, 192.

7. Drzeżdżon, J.; Jacewicz, D.; Sielicka, A.; Chmurzyński, L.; TrAC, Trends Anal. Chem. 2019, 110, 51.

8. Türk, C. T.; Hasçiçek, C.; Gönül, N.; J. Therm. Anal. Calorim. 2009, 95, 865.

9. Schawe, J. E. K.; Thermochim. Acta 2017, 657, 151.

10. Vyazovkin, S.; Chrissafis, K.; Di Lorenzo, M. L.; Koga, N.; Pijolat, M.; Roduit, B.; Sbirrazzuoli, N.; Suñol, J. J.; Thermochim. Acta 2014, 590, 1.

11. Cai, J.; Liu, R.; Ind. Eng. Chem. Res. 2009, 48, 3249.

12. Pérez-Maqueda, L. A.; Criado, J. M.; Gotor, F. J.; Málek, J.; J. Phys. Chem. A 2002, 106, 2862.

13. Sbirrazzuoli, N.; Brunel, D.; Neural Comput. Appl. 1997, 5, 20.

14. Sbirrazzuoli, N.; Girault, Y.; Elegant, L.; Appl. Macromol. Chem. Phys. 1993, 211, 195.

15. Sebastião, R. C. O.; Braga, J. P.; J. Magn. Reson. 2005, 177, 146.

16. Lemes, N. H. T.; Borges, E.; Braga, J. P.; J. Braz. Chem. Soc. 2007, 18, 1342.

17. Sebastião, R. C. O.; Braga, J. P.; Yoshida, M. I.; Thermochim. Acta 2004, 412, 107.

18. Ferreira, B. D. L.; Araújo, N. R. S.; Ligório, R. F.; Pujatti, F. J. P.; Yoshida, M. I.; Sebastião, R. C. O.; Thermochim. Acta 2018, $666,116$.

19. Ferreira, B. D. L.; Silva, V. R.; Jacobsem, B. B.; Yoshida, M. I.; Sebastião, R. C. O.; Quim. Nova 2017, 40, 1149.

20. Sebastião, R. C. O.; Braga, J. P.; Yoshida, M. I.; J. Therm. Anal. Calorim. 2003, 74, 811.

21. Sbirrazzuoli, N.; Girault, Y.; Elégant, L.; Thermochim. Acta 1995, 249, 179.

22. Agência Nacional de Vigilância Sanitária (Anvisa); Resolução da Diretoria Colegiada (RDC) No. 301, Dispõe sobre as Diretrizes Gerais de Boas Práticas de Fabricação de Medicamentos; Diário Oficial da União (DOU), Brasília, de 22/08/2019, p. 64. Available at http://www.in.gov.br/web/dou/-/ resolucao-rdc-n-301-de-21-de-agosto-de-2019-211914064, accessed in February 2020.

23. Pharmaceutical Inspection Co-Operation Scheme (PIC/S); Guide to Good Manufacturing Practice for Medicinal Products Part I; PIC/S Secretariat: Geneva, 2018. Available at https:// www.picscheme.org/layout/document.php?id=1408, accessed in February 2020.

24. Agência Nacional de Vigilância Sanitária (Anvisa); Resolução da Diretoria Colegiada (RDC) No. 166, Dispõe sobre a Validação de Métodos Analíticos e dá outras Providências; Diário Oficial da União (DOU), Brasília, No. 141 de 25/07/2017. Available at http://portal.anvisa.gov.br/documents/10181/2721567/ RDC_166_2017_COMP.pdf/d5fb92b3-6c6b-4130-86704e3263763401, accessed in February 2020.

25. U.S. Department of Health and Human Services; Food and Drug Administration; Center for Drug Evaluation and Research; Center for Veterinary Medicine; Office of Regulatory Affairs; Guidance for Industry PAT-A Framework for Innovative Pharmaceutical Development, Manufacturing, and Quality Assurance; Food and Drug Administration: Rockville, 2004. Available at https://www.fda.gov/media/71012/download, accessed in February 2020.

26. Aucamp, M.; Milne, M.; Eur. J. Pharm. Sci. 2019, 139, 105057.

27. Committee for Human Medicinal Products; International Conference on Harmonization (ICH); Harmonized Tripartite Guideline; Pharmaceutical Development Q8(R2); ICH: London, 2004. Available at https://www.ema.europa.eu/en/documents/ scientific-guideline/international-conference-harmonisationtechnical-requirements-registration-pharmaceuticals-humanuse_en-19.pdf, accessed in February 2020.

28. Goldberg, A. I.; Dunlay, M. C.; Sweet, C. S.; Am. J. Cardiol. 1995, 75, 793.

29. Raghavan, K.; Dwivedi, A.; Campbell Jr., G. C.; Johnston, E.; Levorse, D.; McCauley, J.; Hussain, M.; Pharm. Res. 1993, 10, 900.

30. Wu, L.-S.; Gerard, C.; Hussain, M. A.; Pharm. Res. 1993, 10, 1793.

31. Vyazovkin, S.; Burnham, A. K.; Criado, J. M.; Pérez-Maqueda, L. A.; Popescu, C.; Sbirrazzuoli, N.; Thermochim. Acta 2011, $520,1$.

32. Ozawa, T.; J. Therm. Anal. 1970, 2, 301.

Submitted: November 19, 2019

Published online: February 11, 2020 